\title{
The Study of Teamwork Processes Within the Dynamic Domains of Healthcare: A Systematic and Taxonomic Review
}

\section{OPEN ACCESS}

Edited by:

Leah M. Omilion-Hodges, Western Michigan University, United States

Reviewed by:

James Olumide Olufowote, University of Oklahoma, United States

Douglas Ashwell,

Massey University Business School, New Zealand

${ }^{*}$ Correspondence: Julie V. Dinh Julie.Dinh@baruch.cuny.edu

Specialty section: This article was submitted to Health Communication, a section of the journal Frontiers in Communication

Received: 15 October 2020 Accepted: 05 January 2021

Published: 11 February 2021

Citation:

Dinh JV, Schweissing EJ, Venkatesh A, Traylor AM, Kilcullen MP, Perez JA and Salas E (2021) The Study of Teamwork

Processes Within the Dynamic Domains of Healthcare: A Systematic and Taxonomic Review.

Front. Commun. 6:617928. doi: 10.3389/fcomm.2021.617928

\author{
Julie V. Dinh ${ }^{1,2 *}$, Ethan J. Schweissing ${ }^{3}$, Akshaya Venkatesh ${ }^{3}$, Allison M. Traylor ${ }^{3}$, \\ Molly P. Kilcullen ${ }^{3}$, Joshua A. Perez ${ }^{3}$ and Eduardo Salas ${ }^{3}$
}

${ }^{1}$ Department of Psychology, Baruch College, City University of New York, New York, NY, United States, ${ }^{2}$ The Graduate Center, City University of New York, New York, NY, United States, ${ }^{3}$ Department of Psychological Sciences, Rice University, Houston, TX, United States

Teamwork in healthcare is particularly salient in the dynamic domains of critical care: emergency medicine, surgery, and trauma and resuscitation. Within and across these services, teams must be coordinated to provide optimal care in order to provide optimal delivery of health care. Although many disciplines study teamwork, it is unclear how scholars and clinicians conceptualize, study, and apply these processes. The current systematic review investigates how these fields 1) study teams through the application of a teamwork processes rubric and 2) distinguish themselves from other medical disciplines through the empirical research. We drew upon a taxonomy of teamwork processes (Marks et al., Acad. Manag. Rev. 26, 356 -376; LePine et al., Person. Psychol. 61, 273 -307), operationalizing transition, action, and interpersonal processes, to guide this work. Overall, the dynamic domains of literature studied teamwork processes at high rates, relative to other medical fields. Specifically, they were strongly associated with transition and action processes and the content areas of leadership and performance. Given these emphases, research and practical interventions may want to focus on more interpersonal and collaborative approaches in teamwork

Keywords: critical care, emergency medicine, healthcare, surgery, teamwork processes, teams, trauma and resuscitation

\section{INTRODUCTION}

Events such as the COVID-19 pandemic have drastically transformed the nature of medicine, such that effective teamwork has become of paramount importance. This is particularly true within departments that specialize in acute and emergent care, known as the dynamic domains of healthcare. Within critical care, emergency medicine, and surgical departments, teamwork must be coordinated, both within and across services, in order to provide optimal delivery of health services. Although medicine in general has been moving away from solo practitioner models and toward transdisciplinary systems, this trend is particularly marked within dynamic domains. Nonetheless, although experts agree with the importance of healthcare, it is less evident how teamwork is conceptualized by scholars and clinicians across various stake-holding disciplines. Systematically understanding these operationalizations may help bridge disciplinary differences and guide these domains toward a more integrated application of teamwork processes. 
Researchers across various disciplines have become increasingly interested in teamwork processes in healthcare contexts. Several reviews have examined the impact of medical teamwork on performance and outcomes (e.g., Manser, 2009; Hughes et al., 2016). This focus is especially pronounced in certain domains of medicine, given that particular healthcare specialties rely heavily on team-based models of care. We begin our study with a review of teamwork in the dynamic domains of healthcare and a teamwork processes model. In particular, we describe and apply a taxonomy of teamwork processes, developed by Marks et al. (2001) and LePine et al. (2008). More specifically, we examine transition (between episodes), action (behaviors during performance), and interpersonal (affective and social) teamwork processes. We then implement a systematic literature review of teamwork in healthcare, identifying the unique characteristics and contributions of the dynamic domains, before concluding with implications and directions for future research.

\section{Teamwork in the Dynamic Domains of Healthcare}

Several interdisciplinary bodies of literature are devoted to studying the team, "a distinguishable set of two or more people who interact dynamically, interdependently, and adaptively toward a common and valued goal/objective/ mission" (Salas et al., 1992, p. 4). Many of these scientific and applied stakeholders have emerged from within healthcare systems, given trends that indicate a movement away from single practitioner models and toward multiteam systems.

Although teamwork is core to many areas of healthcare, we focus this review on the three dynamic domains of healthcare-critical care, emergency medicine, and surgery-wherein teamwork processes take on a critical role in overall function and performance (Manser, 2009). Teams in these settings: "work under conditions that change frequently, may be assembled ad hoc, have a dynamically changing team membership, often work together for a short period of time, consist of specialists or several specialist crews, and have to integrate different professional cultures" (Manser, 2009, p. 143). As a result, teamwork in the dynamic domains is highly interdependent, making teamwork processes especially important (Salas et al., 2005), and highly complex, making effective processing more difficult (Xiao et al., 1996). Accordingly, understanding teamwork in the dynamic domains has been a primary focus of teams research in medicine for decades (Xiao et al., 1996). Though teams in other healthcare specialties may share some of these characteristics, the focus of this review is on critical care, emergency medicine, and surgery due to the intense coordination requirements on these teams.

Like their colleagues in medicine, team scientists have also looked at the unique contributions from the dynamic domains of healthcare. They have applied the term "interdisciplinary action team" to describe these groups, given that they combine members with specialized skill sets in settings that require coordinated response to unexpected events (Sundstrom et al., 1990; Fernandez et al., 2008). Indeed, surgical operating theaters, intensive care units, and emergency rooms often see patients with complex, comorbid, or urgent conditions that require role clarity and effective team-based care. Coordination demands on teams in the dynamic domains have thus strongly propelled teamwork research in healthcare.

In particular, team scientists have focused on how medical groups have engaged in teamwork, or the funneling of interdependent actions of individuals toward a common goal (Marks et al., 2001). As an organizing framework, researchers have used the input-mediator-output-input (IMOI) model (Ilgen et al., 2005) to better understand the team dynamics that support effectiveness. Input antecedents at the individual, group, and environmental levels are influenced by mediators. These mediational factors can include emergent states (the developing and existing properties of teams) and teamwork processes (behaviors that directly maintain teamwork; Marks et al., 2001). Mediators then affect outcomes such as group performance and member reactions. These then provide feedback to inputs, funneling back into the IMOI cycle.

\section{Teamwork Processes}

In this review, we focus on teamwork processes for a number of reasons. First, our primary motivation was to uncover how the dynamic domains of healthcare "think" and "talk" about teamwork. Teamwork processes are operationalized as 'members' interdependent acts that convert inputs to outcomes through cognitive, verbal, and behavioral activities directed toward organizing taskwork to achieve collective goals" (Marks et al., 2001, p. 357). These teamwork processes thus provide a clear vehicle for the systematic review of teambased dynamics.

Second, the extensive research on teamwork processes has yielded theoretically and empirically-based taxonomies. Specifically, Marks et al. (2001) and LePine et al. (2008) developed and refined three major dimensions of teamwork processes, respectively. Transition processes occur between performance episodes; team behaviors include mission analysis, goal specification, and strategy formation (LePine et al., 2008). Action processes include activities that occur as teams work toward their goals; these can be organized into the four categories of monitoring progress, system monitoring, team monitoring, and coordinating (Marks et al., 2001; LePine et al., 2008, p. 366). Interpersonal processes manage relationships between team members, including conflict management, motivation, and affect management (Marks et al., 2001; LePine et al., 2008). Altogether, these clear operationalizations provide a critical overarching structure for our systematic review.

Third, our use of teamwork processes also captures key related emergent states that cannot otherwise be sorted into the above framework. For example, researchers (e.g., Marks et al., 2001) have described cohesion as an emergent state. However, during our review of teamwork processes, we categorized cohesion as an interpersonal teamwork process based on its qualitative fit with social group dynamics. Our Methods section further details the development and application of a teamwork processes rubric. 
Ultimately, drawing upon theory of teamwork processes enabled us to develop a directed, systematic, and comprehensive review.

\section{The Current Review}

The current review is an expansion of Dinh et al. (2019)'s systematic and bibliometric review on the interdisciplinary study of teamwork processes within healthcare. The aforementioned review broadly canvassed disciplines, characterizing trends in the study of healthcare teamwork processes. In contrast, the current review focuses exclusively on work published within critical care, emergency medicine, and surgery. This deep dive clarifies the ways in which these dynamic domains characterize and investigate medical teamwork. Because prior research suggests that the dynamic domains may be considered unique from other disciplines and medical specialties, we aim to clarify in what ways teamwork processes may differentiate them from the rest of the clinical landscape. To this end, it explores which of the processes (transition, action, and interpersonal) are valued within dynamic domains, distinguishing them from other disciplinary investigations in teamwork. Additionally, the current review also highlights key constructs that may be essential to understanding teamwork processes within dynamic domains. These variables include other teamwork dynamics (communication and collaboration) and outcomes (leadership and performance).

\section{METHODS}

We conducted a literature search in april 2018, surveying Academic Source Complete, Business Source Premier, PsycINFO, and MEDLINE. We applied Boolean operator keyword searches within the titles and abstracts of peerreviewed journal articles. Specifically, the term "teamwork" was crossed with lexemes relevant to healthcare, such as "healthcare," "medicine," and "clinical." Wildcard operators were applied to ensure that the searches captured all potentially related articles, returning 7,975 for review.

After identifying this first set of articles, we then reviewed abstracts for possible inclusion. The work had to be a peerreviewed journal article written in English. It had to involve a study conducted within a healthcare context, which we operationalized as an environment in which clinical care is delivered (e.g., all domains of medicine and allied health and healthcare professions, including training environments). Given a focus on empirical work, the work had to collect primary data. Importantly, the work also had to involve teamwork as a central topic, i.e., as an independent or dependent variable and/or primary research question. Each of the articles returned in the search was examined to ensure that it met these criteria.

For this investigation of the dynamic domains of healthcare, we investigated these articles using two approaches. First, we looked at eligible articles from the entire range of disciplines (including those from the social sciences, healthcare services, and other fields). Second, we applied the criteria of dynamic domains of medicine, such that the context had to be relevant to dynamic domains, defined as critical or intensive care, emergency
TABLE 1 | Teamwork processes coding rubric.

\begin{tabular}{|c|c|c|}
\hline Process & Definition and components & Key terms \\
\hline Transition & $\begin{array}{l}\text { Processes that occur between performance } \\
\text { episodes } \\
\text { - Mission analysis } \\
\text { - Goal specification } \\
\text { - Strategy formation }\end{array}$ & $\begin{array}{l}\text { Adapt } \\
\text { Debrief } \\
\text { Handoff } \\
\text { Handover } \\
\text { Huddle } \\
\text { Reflexivity } \\
\text { Strategy }\end{array}$ \\
\hline Action & $\begin{array}{l}\text { Activities that occur as teams work toward their } \\
\text { goals } \\
\text { - Monitoring progress } \\
\text { - System monitoring } \\
\text { - Team monitoring } \\
\text { - Coordinating }\end{array}$ & $\begin{array}{l}\text { Backup } \\
\text { Coordinate } \\
\text { Monitor } \\
\text { Support }\end{array}$ \\
\hline Interpersonal & $\begin{array}{l}\text { Management of relationships between team } \\
\text { members } \\
\text { - Conflict management } \\
\text { - Motivation } \\
\text { - Affect management }\end{array}$ & $\begin{array}{l}\text { Affect } \\
\text { Attitude } \\
\text { Cohesion } \\
\text { Conflict } \\
\text { Cooperation } \\
\text { Emotion } \\
\text { Motivation }\end{array}$ \\
\hline
\end{tabular}

Note: Based on LePine et al. (2008) and Marks et al. (2001).

medicine, surgery, and/or trauma and resuscitation (referred to as "trauma" for clarity) environments. Please see Figure 1 for the PRISMA inclusion/exclusion chart.

In the next phase of the review, the authors coded each article using a systematic, synthesizing process. First, one of the authors coded each document's publication year and journal discipline. Second, we used Microsoft Excel software to automatically code content areas related to teamwork processes. This phase involved several stages, including the development of a teamwork process rubric, the generation of key terms, and the automated application of codes to article abstracts.

We began this content coding process by developing a rubric of teamwork key terms. To give our rubric a theoretically-based structure, we used Marks et al. (2001) categories of transition, action, and interpersonal teamwork processes as a framework.

We then populated these three processes with related key terms. We reviewed and incorporated (LePine et al., 2008) meta-analytic model article and coding guide, identifying subconcepts as key terms and using their lexemes to capture all potential forms during coding. Additionally, we also used the word counting feature in ATLAS.ti qualitative software (Scientific Software Development, 2018) to identify the most frequently-cited words across abstracts, titles, and keywords of the included articles. The resulting rubric is shown in Table 1.

Given the synergistic relationship of teamwork dynamics (Ilgen et al., 2005), some teamwork-related terms are overarching and may fit under multiple teamwork processes. Therefore, we included key terms that were independent of the teamwork process categories. These dual processes identified the key terms communication, collaboration, leadership, and performance. 


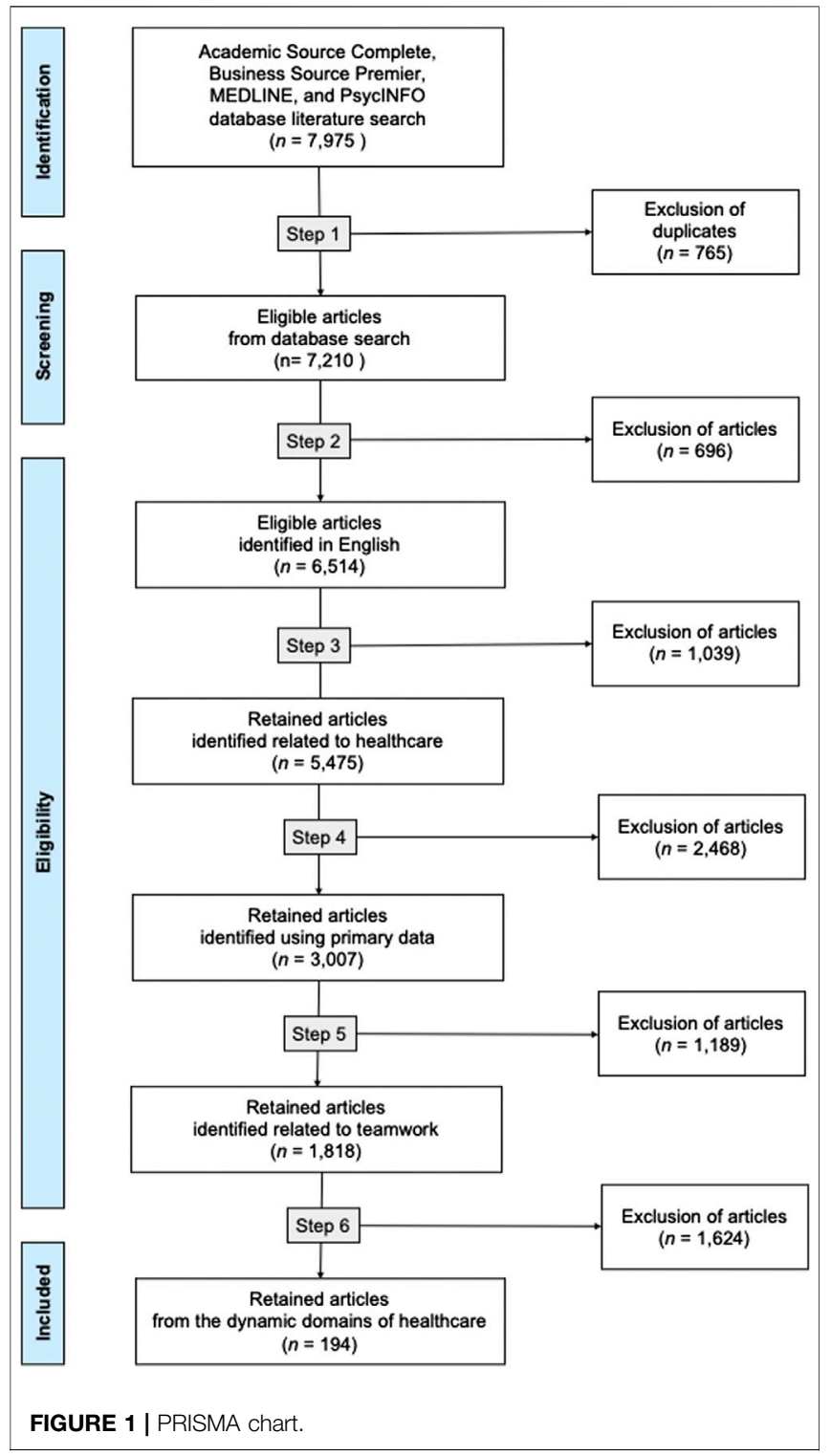

Following the establishment of our coding system, we then coded all article abstracts using a systematic, automated process. We first exported article metadata, including full abstracts, into a data spreadsheet via Zotero. Using Microsoft Excel, we then applied a number of functions to read text and identify and code the existence of key terms within them (combining IF, ISNUMBER, and SEARCH formulas and pivot table visualizations). That is, an article abstract was coded positively (i.e., dummy-coded) for a particular teamwork process if it included at least one corresponding key term. Following this computerized procedure, we then manually reviewed all coding to ensure that it was comprehensive and accurate. Once data was cleaned, we parsed results by disciplines, including within the dynamic domains of medicine.

This method allowed us to quantify large amounts of text, providing us with indices of how various disciplines discussed teamwork processes and content areas. The results of these analyses also served as markers, flagging articles that we could then group and read closely. For a broader overview of the literature (e.g., across all disciplines, rather than only the dynamic domains of healthcare), please see Dinh et al. (2019).

\section{RESULTS}

We identified 1,818 articles eligible for inclusion. Of these, 194 articles were derived from the dynamic domains of healthcare: 34 from critical care, 46 from emergency medicine, 95 articles from surgery, and 19 from trauma and resuscitation. Based on our rubric, each of the four dynamic domains discussed teamwork processes in at least $68.4 \%$ of their published articles.

Next, we compared how dynamic domains may differ in their characterization of teamwork processes from the entire healthcare teamwork literature at large. The dynamic domains focus highly on transition and action processes.

Transition processes were discussed in $18.0 \%$ of articles published in all disciplines total; however, the dynamic domains mentioned these component behaviors at a minimum of $26.3 \%$ (trauma/resuscitation) of their research output. Emergency medicine, critical care, and surgery had the highest rates $(39.1 \%, 35.3 \%$, and $31.6 \%$, respectively).

Action processes were more common across all disciplines, at a rate of $24.5 \%$ across disciplines. Although the team sciences devoted the greatest proportion of their research to this area, it was followed by critical care (38.2\%) and emergency medicine $(34.8 \%)$. Surgery and trauma both reported a research rate of $26.3 \%$, slightly higher than average.

Interestingly, the dynamic domains did not discuss interpersonal processes at or above the cross-disciplinary average of $34.5 \%$. In fact, trauma and surgery and trauma demonstrated rates among the lowest of all disciplines $(15.8 \%$ and $20 \%)$. Critical care and emergency medicine's rates were also below average (26.5\% and $28.2 \%$ ).

We then investigated more universal teamwork behaviors. Surgery led the cross-disciplinary conversation on communication, with a rate of $61.0 \%$ of their articles mentioning the term. Other dynamic domains did not necessarily reflect this trend. Critical care and trauma mentioned communication at rates lower than the $44.3 \%$ average $(32.4 \%$ and $31.6 \%$, respectively), while emergency medicine was closer to the mean $(47.8 \%)$. Collaboration was also not discussed highly within the dynamic domains. Across disciplines, the average proportion of articles mentioning collaboration was $24.5 \%$. Here, trauma and surgery's rates of collaboration research was among the lowest, at $15.8 \%$ and $10.5 \%$ respectively. Critical care $(23.5 \%)$ and emergency medicine $(21.7 \%)$ were also slightly below average.

The final two keywords were not necessarily associated with teamwork processes, given that they are often more associated with inputs and outputs. However, given their incidence in the literature, their emergence in our qualitative analyses of common terms, and their consequent demonstrable interest to researchers, they merit mention here. Two dynamic domains, emergency medicine and trauma, mentioned leadership at the highest 
TABLE 2 | Findings by teamwork process and dynamic domain.

\begin{tabular}{|c|c|c|c|c|}
\hline $\begin{array}{l}\text { Process } \\
\text { type }\end{array}$ & Critical care $(k=34)$ & Emergency medicine $(k=46)$ & Surgery $(k=95)$ & Trauma/Resuscitation $(k=19)$ \\
\hline Overview & $\begin{array}{l}\text { - These articles included varying levels of } \\
\text { professionals (e.g., students, residents, } \\
\text { diverse teams) } \\
\text { - The majority pertained specifically to critical } \\
\text { care, but there are a number of } \\
\text { interdisciplinary articles }\end{array}$ & $\begin{array}{l}\text { - These studies varied in which level was } \\
\text { addressed, though a relatively high number } \\
\text { touched on doctor-nurse relationships }\end{array}$ & $\begin{array}{l}\text { - Research in this domain examined different } \\
\text { levels of professionals, such as residents and } \\
\text { students }\end{array}$ & $\begin{array}{l}\text { - Research discussed processes between } \\
\text { interdisciplinary and interprofessional teams } \\
\text { within trauma }\end{array}$ \\
\hline Transition & $\begin{array}{l}\text { - There was a focus on strategies, as well as an } \\
\text { emphasis on hand-off between members of } \\
\text { the same team } \\
\text { - A number of articles analyzed how burn out/ } \\
\text { stress impeded patient care. This implies } \\
\text { stress may occur at a higher rate during } \\
\text { transition process }\end{array}$ & $\begin{array}{l}\text { - Non-technical skills are emphasized as critical } \\
\text { for improving quality of care, and in some } \\
\text { cases provider satisfaction } \\
\text { - Many articles specifically mentioned } \\
\text { challenges to and strategies to improve } \\
\text { communication }\end{array}$ & $\begin{array}{l}\text { - There was an emphasis on debriefing between } \\
\text { episodes, with some mention of handoff } \\
\text { - There was a focus on teamwork and } \\
\text { communication in the operating room. } \\
\text { Specific strategies included simulations, } \\
\text { TeamSTEPPs, interviews, and surveys to } \\
\text { improve teamwork and communication skills }\end{array}$ & $\begin{array}{l}\text { - Debriefing and strategy were emphasized } \\
\text { - Transition practices drew upon crew resource } \\
\text { management (CRM), simulations, and } \\
\text { communication analysis, finding that these had } \\
\text { positive effects on team dynamics } \\
\text { - Articles largely focused on communication } \\
\text { within teams }\end{array}$ \\
\hline Action & $\begin{array}{l}\text { - Support was discussed at a high rate } \\
\text { - Training simulations were used most often to } \\
\text { improve team performance/overall teamwork, } \\
\text { benefitting both technical and non-technical } \\
\text { skills }\end{array}$ & $\begin{array}{l}\text { - Articles emphasized the importance of } \\
\text { support } \\
\text { - Programs such as TeamSTEPPs 1, EMT- } \\
\text { TEAMWORK, and MHPTS were used } \\
\text { - There was heavy use of classes/simulations to } \\
\text { train technical and non-technical skills }\end{array}$ & $\begin{array}{l}\text { - Coordination was mentioned most frequently } \\
\text { - Simulations (MDAC, MMOR), TeamSTEPPs, } \\
\text { surveys, other evaluation tools (TPOT), and } \\
\text { interviews were used to improve teamwork } \\
\text { dynamics }\end{array}$ & $\begin{array}{l}\text { - Support was a key mechanism of teamwork } \\
\text { - Articles used various surveys, interviews and } \\
\text { pre-existing measures to identify } \\
\text { communication patterns and other team- } \\
\text { related skills }\end{array}$ \\
\hline Interpersonal & $\begin{array}{l}\text { - Research mostly investigated relationships } \\
\text { among health care providers } \\
\text { - A number of articles mentioned burnout in } \\
\text { teams. For example, emotional distress can be } \\
\text { "contagious" among a team (Piquette et al. } \\
\text { 2009) } \\
\text { - The link between interpersonal relationships } \\
\text { among providers and patient safety was } \\
\text { emphasized }\end{array}$ & $\begin{array}{l}\text { - Studies emphasized the importance of clear } \\
\text { verbal communication and offered solutions } \\
\text { for communication barriers } \\
\text { - A positive working relationship is necessary for } \\
\text { useful collaboration in a healthcare team }\end{array}$ & $\begin{array}{l}\text { - Attitudes were emphasized in a number of } \\
\text { articles } \\
\text { - Studies primarily included medical professionals } \\
\text { as team entities, although teams were } \\
\text { interdisciplinary and included a range of levels, } \\
\text { (e.g., surgeons and trainees) } \\
\text { - Communication, in general, between team } \\
\text { members was studied, and was evaluated using } \\
\text { surveys and interviews }\end{array}$ & $\begin{array}{l}\text { - There was a limited number of studies in this } \\
\text { area, suggesting more research is required }\end{array}$ \\
\hline
\end{tabular}


proportions across all disciplines ( $45.7 \%$ and $42.1 \%$, respectively). Surgery also touched upon leadership in over a third of its teamwork research $(34.7 \%)$. Critical care was closer to the average of $24.1 \%$, at $23.6 \%$. All four dynamic domains discussed performance at the highest proportions of all disciplines. This was led by surgery $(52.6 \%)$ and followed by emergency medicine $(47.8 \%)$, trauma $(47.4 \%)$, and critical care $(41.1 \%)$.

\section{DISCUSSION}

Our review of the literature has supported the notion that the dynamic domains study teamwork processes in distinct manners. Based on the bodies of work within their journals, dynamic domains were among the disciplines that focused most highly and empirically on operationalized teamwork processes (relative to general medicine, primary care, and specialty medicine, as well as other non-medical disciplines). Moreover, these disciplines shared common characteristics that distinguished the nature of their work. However, we also note that each dynamic domain also characterized teamwork processes in idiosyncratic ways, as shown in Table 2 and discussed throughout this section. Our results align with previous research on these specialties, which has defined these healthcare contexts as especially meaningful to teams.

Furthermore, the dynamic domains demonstrate a particular interest in specific types of teamwork. Critical care, emergency medicine, surgery, and trauma were all associated strongly with both transition and action processes and the content areas of leadership and performance. Indeed, publications within these disciplines often touch upon several of these thematic areas simultaneously. One critical care study assessed a teamwork simulation using behavioral factors of "leadership and team coordination" and "verbalizing situational information" (Frengley et al., 2011). In emergency medicine, a nontechnical skills teamwork training was evaluated using measures of leadership, teamwork, and task management (Porter et al., 2018). Finally, a surgical training on postoperative care examined outcomes including teamwork, leadership, and measures of clinical performance (Arora et al., 2015). Evidently, these fields thus prioritize teamwork as it relates to continuity of care, authority, and outcomes. Notably, too, these exemplars not only relate to content areas characteristic of the specialties, but also illustrate how teamwork is being integrated into provider education.

Given the findings from previous theory and empiricism and our own systematic review, it is unsurprizing that these subgroups of medicine emerged as distinct research players in the healthcare teamwork field. Moreover, the relevant content areas identified in our study align with the characterization of such dynamic domains. Transition processes, including forming strategies, debriefing, and hand-off, would be especially important in the coordination of these interdisciplinary, expert teams. For example, over half of the articles identified within surgery mentioned debriefing practices. Furthermore, due to the environmental entropy, high stakes, and delivery of care that often distinguish critical care, emergency medicine, and surgery, strong leadership and outcomes are also necessarily emphasized therein.

Just as important as what these dynamic domains focused upon is what they did not study. In particular, interpersonal processes were infrequently studied by the dynamic domains. In a related systematic review, Dinh et al. (2019) found that interprofessional and interdisciplinary journals emphasized affective and attitudinal competencies around teamwork, including cooperation and cohesion. These findings intuitively make sense, given that such stakeholders in these fields must often adapt to diverse medical subfields and settings. However, within the highly structured dynamic domains, it is possible that emotional components of teamwork may be less pressing than the behaviors involved in transition or action processes. However, in such high-stakes environments, providers may often be susceptible to stress, burnout and other negative affective dynamics (e.g., Lloyd et al., 1994; Chen et al., 2013)-the effects of which can be offset by teamwork. Understanding and improving interpersonal teamwork processes is particularly important as they have direct (e.g., patient satisfaction) and indirect (e.g., ineffective problem-solving, employee burnout leading to preventable error) implications for patients.

For example, interpersonal processes such as conflict management may be particularly important for healthcare teams, as conflict is a consistent and unavoidable issue in this context. Common causes of conflict in dynamic domains, such as within emergency departments, include poor communication, external stressors, being disengaged, and self-serving behaviors (Chan et al., 2014). Previous research indicates that interpersonal conflict is associated with burnout in healthcare (Abrahamson et al., 2009; Dubale et al., 2019). Addressing these issues involves uncovering the causes of conflict, engaging in effective management, and utilizing positive approaches to conflict resolution (McKibben, 2017). Interpersonal teamwork processes that focus on empathy, effective collaboration, and engagement can therefore help mitigate detrimental effects of conflict (Chan et al., 2014).

Given important but understudied interpersonal teamwork processes, researchers and practitioners may consider incorporating such themes into future work in several ways. Pragmatically, it is necessary to continue establishing the importance of these affective and attitudinal dynamics to medical institutions, including through empirical research on engagement and effectiveness. Theoretically, it would be useful to develop a clearer, more comprehensive framework or taxonomy of interpersonal teamwork processes. Logistically, these constructs can be kept at the forefront by being inserted into existing and future work. For example, in team studies and evaluations, the addition of relatively lowinvestment affective and attitudinal outcomes in members can provide information on group dynamics. Ultimately, the dynamic domains may benefit from researching and enacting the affective management of member affect and conflict. 
Another area of deficiency is collaboration, defined as an evolving process where individuals actively and reciprocally engage in joint activities aimed at achieving one goal (Bedwell et al., 2012). However, collaboration may not be a focal point for the highly structured and/or hierarchical environments such as those within the surgical operating theater. Nonetheless, it is interesting that collaboration did not emerge as a more studied topic in the intensive care unit, given that the setting is a "nexus for interspecialty and interdisciplinary tensions" (Lingard et al., 2004, p. R403). This lower rate of research suggests a gap in the literature that can be served by future research.

Interestingly, surgery journals cited communication at higher, but collaboration at lower, rates than did other fields. While these two content areas of communication and collaboration can be interrelated, there are important distinctions. For example, several studies investigated the feasibility and acceptability of surgical checklists; the implementation thereof typically requires proceduralized order-giving (communication) as opposed to participatory information-sharing (collaboration). In a study of 10 hospitals, Singer et al. (2016) evaluated interventional efficacy through surgeon buy-in, clinical leadership, communication, and teamwork ratings. Considering these findings in sum, it appears that surgical teamwork focuses on formal, hierarchical processes of conveying information and coordinating action.

Future studies can address the limitations of this work. First, this study only examined primary data. Upcoming work can include other contributions in the healthcare teamwork space, including qualitative and theoretical pieces. Relatedly, our search terms required mention of teamwork; other studies can look more broadly at operationalizations of group-based care. Second, the large-scale, automated application of a rubric inherently involves some loss of detail. Although we manually reviewed coding to enhance accuracy and conducted closer readings, traditional qualitative methods may lead to more comprehensive analyses and more detailed findings.

These factors notwithstanding, our study makes several contributions. It distinguishes the dynamic domains from

\section{REFERENCES}

Abrahamson, K., Jill Suitor, J., and Pillemer, K. (2009). Conflict between nursing home staff and residents' families: does it increase burnout?. J. Aging Health 21 (6), 895-912. doi:10.1177/0898264309340695

Arora, S., Hull, L., Fitzpatrick, M., Sevdalis, N., and Birnbach, D. J. (2015). Crisis management on surgical wards: a simulation-based approach to enhancing technical, teamwork, and patient interaction skills. Ann. Surg. 261, 888-893. doi:10.1097/SLA.0000000000000824

Bedwell, W. L., Wildman, J. L., DiazGranados, D., Salazar, M., Kramer, W. S., and Salas, E. (2012). Collaboration at work: an integrative multilevel conceptualization. Hum. Resour. Manag. Rev. 22 (2), 128-145. doi:10.1016/j. hrmr.2011.11.007

Chan, T., Bakewell, F., Orlich, D., and Sherbino, J. (2014). Conflict prevention, conflict mitigation, and manifestations of conflict during emergency department consultations. Acad. Emerg. Med. 21 (3), 308-313. doi:10.1111/ acem. 12325

Chen, K. Y., Yang, C. M., Lien, C. H., Chiou, H. Y., Lin, M. R., Chang, H. R., et al. (2013). Burnout, job satisfaction, and medical malpractice among physicians. Int. J. Med. Sci. 10, 1471. doi:10.7150/ijms.6743 other disciplines in terms of how these fields study teamwork. In doing so, this work also identifies areas for future growth, including within the topics of interpersonal processes and collaboration. This review also uses a novel, computer-assisted methodology to parse through large volumes of data, which can be used in other studies for similar purposes (see Dinh et al., 2019, for recommendations regarding this approach).

Ultimately, this study underscores the importance of teamwork in critical care, emergency medicine, surgery, and trauma and resuscitation teams. Specifically, these dynamic domains are characterized by their research focus on transition and action processes. Communication appears to be especially important to surgical teams. Given their relatively low area of emphasis, interpersonal teamwork processes and collaboration present areas for future research. Leadership and performance also emerged as burgeoning topics of interest for these fields. Overall, this review demonstrates the unique contributions of healthcare teamwork research from the dynamic domains, while simultaneously highlighting room for growth.

\section{DATA AVAILABILITY STATEMENT}

The original contributions presented in the study are included in the article/Supplementary Material.

Further in quiries can be directed to the corresponding author.

\section{AUTHOR CONTRIBUTIONS}

All authors were substantially engaged in the scientific development, study implementation, and/or manuscript preparation. JD, AT, and ES designed the study. JD, EJS, AV, AT, MK, and JP coded the data. JDES, and AV wrote the paper and analyzed the data. EJS, AV, AT, and ES edited the paper.

Dinh, J. V., Traylor, A. M., Kilcullen, M. P., Perez, J. A., Schweissing, E. J., Venkatesh, A., et al. (2019). Cross-disciplinary care: a systematic review on teamwork processes in healthcare. Small Group Res. 51 (1), 125-166. doi:10. $1177 / 1046496419872002$

Dubale, B. W., Friedman, L. E., Chemali, Z., Denninger, J. W., Mehta, D. H., Alem, A., et al. (2019). Systematic review of burnout among healthcare providers in sub-Saharan Africa. BMC Publ. Health 19 (1), 1247-1267. doi:10.1186/s12889019-7566-7

Fernandez, R., Kozlowski, S. W., Shapiro, M. J., and Salas, E. (2008). Toward a definition of teamwork in emergency medicine. Acad. Emerg. Med. 15, 1104-1112. doi:10.1111/j.1553-2712.2008.00250.x

Frengley, R. W., Weller, J. M., Torrie, J., Dzendrowskyj, P., Yee, B., Paul, A. M., et al. (2011). The effect of a simulation-based training intervention on the performance of established critical care unit teams. Crit. Care Med. 39, 2605-2611. doi:10.1097/CCM.0b013e3182282a98

Henderson, A. M., Gregory, M. E., Joseph, D. L., Sonesh, S. C., Marlow, S. L., Lacerenza, C. N., et al. (2016). Saving lives: a meta-analysis of team training in healthcare. J. Appl. Psychol. 101, 1266-1304. doi:10.1037/apl0000120

Ilgen, D. R., Hollenbeck, J. R., Johnson, M., and Jundt, D. (2005). Teams in organizations: from input-process-output models to IMOI models. Annu. Rev. Psychol. 56, 517-543. doi:10.1146/annurev.psych.56.091103.070250 
LePine, J. A., Piccolo, R. F., Jackson, C. L., Mathieu, J. E., and Saul, J. R. (2008). A meta-analysis of teamwork processes: tests of a multidimensional model and relationships with team effectiveness criteria. Person. Psychol. 61, 273-307. doi:10.1111/j.1744-6570.2008.00114.x

Lingard, L., Espin, S., Evans, C., and Hawryluck, L. (2004). The rules of the game: interprofessional collaboration on the intensive care unit team. Crit. Care 8, R403. doi:10.1186/cc2958

Lloyd, S., Streiner, D., and Shannon, S. (1994). Burnout, depression, life and job satisfaction among canadian emergency physicians. J. Emerg. Med. 12, 559-565. doi:10.1016/0736-4679(94)90360-3

Manser, T. (2009). Teamwork and patient safety in dynamic domains of healthcare: a review of the literature. Acta Anaesthesiol. Scand. 53, 143-151. doi:10.1111/j. 1399-6576.2008.01717.x

Marks, M. A., Mathieu, J. E., and Zaccaro, S. J. (2001). A temporally based framework and taxonomy of team processes. Acad. Manag. Rev. 26, 356-376. doi:10.5465/AMR.2001.4845785

McKibben, L. (2017). Conflict management: importance and implications. $\mathrm{Br}$. J. Nurs. 26 (2), 100-103. doi:10.12968/bjon.2017.26.2.100

Porter, J. E., Cant, R. P., and Cooper, S. J. (2018). Rating teams' non-technical skills in the emergency department: a qualitative study of nurses' experience. Int. Emerg. Nurs. 38, 15-20. doi:10.1016/j.ienj.2017.12.006

Piquette, D., Reeves, S., and LeBlanc, V. R. (2009). Stressful intensive care unit medical crises: how individual responses impact on team performance. Crit Care Med, 37 (4), 1251-1255. doi:10.1097/CCM. 0b013e31819c1496

Salas, E., Dickinson, T. L., Converse, S. A., and Tannenbaum, S. I. (1992). “Toward an understanding of team performance and training," in Teams: their training and performance. Editors R. W. Swezey and E. Salas (Norwood, NJ: Ablex Publishing Corporation), 3-29.

Salas, E., Sims, D. E., and Burke, C. S. (2005). Is there a "big five" in teamwork?. Small Group Res. 36 (5), 555-599. doi:10.1177/1046496405277134

Scientific Software Development (2018). Berlin: ATLAS.ti Version 8.1.3.

Singer, S. J., Molina, G., Li, Z., Jiang, W., Nurudeen, S., Kite, J. G., et al. (2016). Relationship between operating room teamwork, contextual factors, and safety checklist performance. J. Am. Coll. Surg. 223, 568-e2. doi:10.1016/j.jamcollsurg. 2016.07.006

Sundstrom, E., De Meuse, K. P., and Futrell, D. (1990). Work teams: applications and effectiveness. Am. Psychol. 45, 120.

Xiao, Y., Hunter, W. A., Mackenzie, C. F., Jefferies, N. J., Horst, R. L., and Group, L. (1996). Task complexity in emergency medical care and its implications for team coordination. LOTAS group. level one trauma anesthesia simulation. Hum. Factors 38 (4), 636-645. doi:10.1518/001872096778827206

Conflict of Interest: The authors declare that the research was conducted in the absence of any commercial or financial relationships that could be construed as a potential conflict of interest.

Copyright (C) 2021 Dinh, Schweissing, Venkatesh, Traylor, Kilcullen, Perez and Salas. This is an open-access article distributed under the terms of the Creative Commons Attribution License (CC BY). The use, distribution or reproduction in other forums is permitted, provided the original author(s) and the copyright owner(s) are credited and that the original publication in this journal is cited, in accordance with accepted academic practice. No use, distribution or reproduction is permitted which does not comply with these terms. 